\title{
WASHING PRECIPITATES FOR PEPTIZATION
}

BY HARRY N. HOLMES AND R. E. RINDFCSZ

The peptization of insoluble compounds has become an interesting part of laboratory work with colloids. A common annoyance in such work is the difficulty of removing adsorbed ions. Unless the precipitate can be purified its subsequent peptization is complicated.

The flocculent or semi-gelatinous ferric arsenate and ferric phosphate are examples of precipitates difficult to free from their adsorbed ions. In the course of an investigation on the peptization of these two compounds we found it necessary to develop a working method of securing rather pure ferric arsenate and ferric phosphate and we believe the results may be of value to those interested in colloids.

For peptization purposes we precipitated ferric arsenate of the formula $\mathrm{Fe}_{2}\left(\mathrm{HAsO}_{4}\right)_{3}$ by adding an excess of dipotassium arsenate solution to ferric chloride solution. The precipitate, transferred to the filter, could not be washed free from the excess of dipotassium arsenate or the potassium chloride. Even when fresh washings gave weak tests for the arsenate ion if the precipitate was allowed to stand for some time under water and then filtered the washings contained plenty of soluble arsenate. The fresh precipitate was flocculent or semi-gelatinous and light yellow in color. With washing on the filter the color deepened and the arsenate became almost gelatinous. Cracks developed. The physical condition of the ferric arsenate was very favorable to powerful adsorption of ions.

It was thought that the washing out of adsorbed ions could be facilitated if the precipitate was disintegrated by suitable mechanical means. Violent shaking with water and clean sand was tried with interesting results. Sea sand was sifted on a 6o-mesh screen and the grains sifting through rejected. The rest was heated with pure $6 N$ hydrochloric acid for ten hours on the water bath. The acid was changed 
three times and finally washed out with water. This treatment removed most of the magnetite.

In all our experiments the ferric arsenate was precipitated by adding $30 \mathrm{cc}$ of a solution of dipotassium arsenate containing I.7226 grams of arsenic and $\mathrm{io} c c$ of solution ferric chloride containing 0.1396 gram of iron to $160 \mathrm{cc}$ of water. These proportions insured the presence of a large excess of dipotassium arsenate. For the sand shaking experiments the total volume of $200 \mathrm{cc}$, precipitate and all, was placed in a $500 \mathrm{cc}$ cylinder with Io grams of the clean sand. The cylinder was rubber stoppered as glass stoppers permitted sand to work in between stopper and neck. The shaking (by hand) continued for three minutes at a uniform rate of Ioo shakes per minute. After standing over night, or I4 hours, Ioo cc of the clear supernatant liquid was drawn off with a pipette, filtered and the filtrate analyzed for soluble arsenate. The filter paper was then perforated and any small particles of ferric arsenate washed back into the $5^{\circ 0}$ cc cylinder with Ioo $\mathrm{cc}$ of water. This maintained the volume of $200 \mathrm{cc}$ exclusive of the Io grams of sand. The operation of shaking for three minutes, letting stand one hour to settle, removing Ioo cc of clear supernatant liquid, filtering, analyzing the filtrate for soluble arsenate and replacing the roo $\mathrm{cc}$ by enough water to maintain the volume at $200 \mathrm{cc}$ was repeated ten times. At this point it was necessary to let the material stand over night, or I4 hours. The usual operation was repeated ten times the next day. The last time the contents of the cylinder were thrown on the filter paper and the filtrate analyzed for the twentieth determination. It was not difficult to tilt the cylinder so that the wet sand stuck to the wall while the precipitate ran out.

The results are tabulated with those of similar experiments in shaking without sand, in decanting without shaking and in washing the precipitate on the filter paper. The procedure for the shaking without sand was exactly the same as above. The disintegrating action of the sand was absent 
but the results show considerable breaking down of the larger masses of ferric arsenate.

The experiments with washing the precipitate on the filter took less time. The $30 \mathrm{cc}$ of potassium arsenate solution were added to Io $\mathrm{cc}$ of ferric chloride solution and the mixture immediately thrown on the filter. Enough hot water was quickly poured on the filter to give Ioo $\mathrm{cc}$ of filtrate. In practice about $75 \mathrm{cc}$ was found sufficient. The aim in getting Ioo cc of wash water was to make the different series comparable. This filtrate was set aside to be analyzed for soluble arsenate. As soon as Ioo cc of wash water ran through IOC $\mathrm{cc}$ of hot water was immediately added to the ferric arsenate on the filter paper. This was continued for twenty washings allowing no time to elapse between washings. All these wash waters were analyzed at the same time.

In the decanting series the $200 \mathrm{cc}$ total volume of precipitate and solution was allowed to stand over night or I4 hours. There was no shaking, merely the stirring caused by pouring one solution into the other. With a pipette Ioo ce of clear supernatant liquid was drawn off, filtered and analyzed for soluble arsenate. As usual, a hole was punched in the filter paper and any traces of ferric arsenate washed back into the cylinder with IoO ce of water. This restored the original volume of $2 \mathrm{co} \mathrm{cc}$. After settling for an hour another $\mathrm{I} O \mathrm{cc}$ of clear liquid was removed by the pipette and the whole procedure repeated hourly for ten washings or decantings. For the elerenth the precipitate settled over night or I4 hours. Ten more hourly decantings the next day gave a total of twenty wash waters to analyze for arsenate. For the twentieth washing the usual roo $\mathrm{cc}$ of water was not added but the cylinder emptied on the filter. About $85 \mathrm{cc}$ filtered through and this was analyzed.

In all these experiments hot water was added. The method of analysis used was the precipitation of silver arsenate, its solution in nitric acid and titration with ammonium thiocyanate using ferric alum as an indicator.

In the following table the amount of arsenate removed 
by each washing is added to the amount removed by all previous washings. In other words, each number represents the total amount removed up to and including that treatment. No. 3, for example, represents the total amount of arsenate removed by the first, second and third washings.

TABLE I

Increasing Totals of Adsorbed Potassium Arsenate Remored by Successive Washings

Estimated as Arsenic

\begin{tabular}{|c|c|c|c|c|}
\hline No. & $\begin{array}{c}\text { Shaking with } \\
\text { sand } \\
\text { Grams }\end{array}$ & $\begin{array}{l}\text { Shaking with- } \\
\text { out sand } \\
\text { Grams }\end{array}$ & $\begin{array}{c}\text { Washing on } \\
\text { filter } \\
\text { Grams }\end{array}$ & $\begin{array}{c}\text { Decanting with- } \\
\text { out shaking } \\
\text { Grams }\end{array}$ \\
\hline I & 0.6683 & 0.6218 & 0.9856 & 0.5362 \\
\hline 2 & I. OI 80 & 0.9793 & I. $256 \mathrm{I}$ & $0.8 \mathrm{I}+5$ \\
\hline 3 & I. I944 & I. 1627 & I. 3276 & $0.94+\mathrm{I}$ \\
\hline+ & I. $286 \mathrm{I}$ & I . $259 \mathrm{I}$ & I. 3548 & I. .0356 \\
\hline 5 & I. 3366 & I. 3 I I 2 & I. 3662 & I .0994 \\
\hline 6 & I. 3655 & I. 3422 & I. 3699 & I .1475 \\
\hline 7 & I. 3816 & I. 3600 & I. 3730 & I. 1836 \\
\hline 8 & I. 3926 & 1.3710 & I. 3753 & I. 2106 \\
\hline 9 & I. 4004 & I. $379 \mathrm{I}$ & I. $37-6$ & I. 23 I 8 \\
\hline IO & I. 4060 & I. 3850 & I. 3804 & I. $3+60$ \\
\hline I I & $\mathrm{I} \cdot+102$ & I. 3999 & I. 3838 & I. 2569 \\
\hline $\mathrm{I} 2$ & I +129 & I. 3935 & I. 3857 & I. 2659 \\
\hline 13 & $1+160$ & I. 3967 & I . 3869 & I. 27,09 \\
\hline I 4 & I. 4188 & I . 3995 & I. 3883 & I. 2754 \\
\hline I 5 & I. 42 I 2 & I. 4023 & I. 3809 & I. 2798 \\
\hline 16 & I. 4244 & I. 4046 & I .39 I 3 & I. 2825 \\
\hline 17 & I. +266 & 1.4065 & I. 3938 & I. $285 I$ \\
\hline 18 & I. 4290 & I. 4084 & I. 3953 & I. 2879 \\
\hline 19 & I. 4304 & I. 4102 & I. 3966 & I. 2907 \\
\hline 20 & I. $43^{2}+$ & I 4 II 8 & I. 3983 & I. 2943 \\
\hline
\end{tabular}

Naturally the first "Washing on the filter" removed much more than the other treatments because most of the wash water filtered through. In the other experiments only half of the wash water was removed each time. In spite of this on the seventh treatment the total amount of adsorbed but soluble arsenate removed was greatest in "Shaking with sand" series and this lead was maintained to the end. The total removed in twenty treatments was 1.4324 grams (esti- 
mated as arsenic) by the "Shaking with sand" series, I.4I I 8 grams by the "Shaking without sand" series, I.3983 grams by the "Washing on filter" series, and I.2943 grams by the "Decanting without shaking" series. The excess arsenic to be washed out was I.437 I grams.

It is evident that to secure the purest precipitate of a flocculent or semi-gelatinous nature the method of shaking with sand and water is the most effective. For rapid work in securing only a moderately pure precipitate the usual method of washing on the filter is probably most satisfactory.

The results of the preceding experiments suggested three more. Using the same quantities of potassium arsenate and ferric chloride solutions as before, enough water was added to make the total volume $1900 \mathrm{cc}$. This was shaken in a flask with io grams of clean sand as previously described and transferred to a tall cylinder. The flask was rinsed twice with $50 \mathrm{cc}$ of water, making the total volume $2000 \mathrm{cc}$. After settling I 2 hours I 800 cc of the clear supernatant liquid was drawn off and analyzed as usual. The removal of I . 2 I 47 grams of soluble arsenate (estimated as arsenic) was more effective than in any of the previous experiments for the first treatment. Of course the gain was due to the removal of nine-tenths of the arsenate solution as compared with half in the other experiments. Such a fraction was not possible with a total volume of $200 \mathrm{cc}$ because the flocculent precipitate occupied too great a volume.

An experiment similar to the above, using a volume of $2000 \mathrm{cc}$ but without sand as a disintegrator, showed the removal of I . I 826 grams of the excess arsenate in a single treatment, also a much better showing than those in the table.

The final experiment was the addition of Io grams of clean sand and $80 \mathrm{cc}$ of water to the usual $40 \mathrm{cc}$ volume of the mixed potassium arsenate and ferric chloride solutions. This was then shaken as indicated and everything but the sand thrown on a large filter. The filtrate, roo cc., was analyzed and showed the removal of 1.2687 grams of excess arsenate. This extremely effective removal of adsorbed 
ions was plainly due to the disintegrating effect of the shaking with sand.

The conclusion is that the colloid student anxious to free a flocculent precipitate from adsorbed ions has two good methods at his disposal. The precipitate may be shaken in a large flask with nearly two liters of water, transferred to a tall cylinder, let settle over night, all the clear supernatant liquid removed and the treatment repeated as often as desired.

A better method is to shake the precipitate with a few grams of clean sand and as much hot water as the filter paper will hold, throw everything but the sand on the filter to drain, again transfer the precipitate to the shaking bottle, add hot water, shake, filter and repeat as many times as may seem necessary. This is the most rapid and the most effective method. If desired, the shaking may be managed without the sand. The washing will still be very rapid and effective.

Oberin College

Oberlin, $O$. 